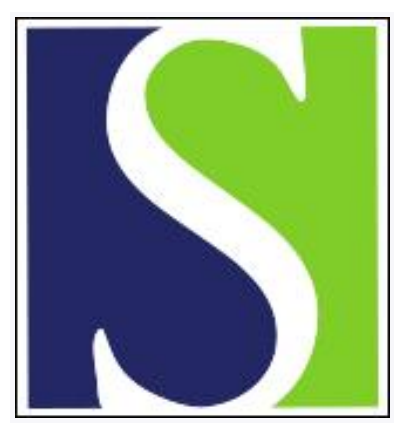

Scand J Work Environ Health 1985;11(6):439-446

https://doi.org/10.5271/sjweh.2202

Issue date: Dec 1985

Thermal oxidation of polycyclic aromatic hydrocarbons adsorbed on alumina.

by Alfheim I, Kveseth K, Ramdahl T, Rob J

This article in PubMed: www.ncbi.nlm.nih.gov/pubmed/4095522

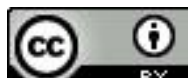




\title{
Thermal oxidation of polycyclic aromatic hydrocarbons adsorbed on alumina
}

\author{
by Ingrid Alfheim, PhD, ${ }^{1}$ Kari Kveseth, PhD, ${ }^{1}$ Thomas Ramdahl, PhD, ${ }^{1}$ \\ Jan Rob, MSc(ChemEng) ${ }^{2}$
}

\begin{abstract}
ALFHEIM I, KVESETH K, RAMDAHL T, ROB J. Thermal oxidation of polycyclic aromatic hydrocarbons adsorbed on alumina. Scand $J$ Work Environ Health 11 (1985) 439-446. The reevaporation of polycyclic aromatic hydrocarbons (PAH) from secondary alumina (alumina used in a fluidized bed for pot gas cleaning) used in the production of aluminum in aluminum reduction plants has been studied. The secondary alumina contains around $100 \mathrm{ppm}$ of PAH when introduced to the pots. The results of this study indicate that only a minor part of the adsorbed $\mathrm{PAH}$ is reevaporated at the pot temperature of $300-400^{\circ} \mathrm{C}$ and that the use of secondary alumina has little effect on the PAH concentration in the workplace atmosphere of the aluminum reduction plants.
\end{abstract}

Key terms: air pollution, aluminum reduction, pot gas cleaning, reevaporation, secondary alumina, workplace atmosphere.

The occurrence of polycyclic aromatic hydrocarbons (PAH) in the work atmosphere of aluminum reduction plants $(3,4,5,10,12)$ and in the emissions from such plants (1) is well established. The PAH is formed during the electrolysis process by pyrolysis of the coal tar pitch and coke which constitute the electrodes used in the Söderberg process.

The emission of fluoride has been considered the most serious environmental problem caused by aluminum smelting. Pot gas cleaning through a fluidized bed of alumina (primary alumina) has greatly reduced the fluoride emission. The alumina in the cleaning system also adsorbs some of the emitted PAH. After passing through the cleaning system, the alumina (now called secondary alumina) is added to the electrolysis pots.

The analysis of several extracts from secondary alumina has shown it to contain PAH in concentrations around $100 \mathrm{ppm}$. The recognition of such relatively high concentrations of PAH in the alumina has caused some concern about the possible impact of the alumina-bound PAH on the total concentration of PAH in the workplace atmosphere. As the alumina, when added to the pots, is heated to $300-400^{\circ} \mathrm{C}$, it was feared that the adsorbed PAH might evaporate and increase the ambient concentrations of these unwanted compounds in the workplace atmosphere.

The present study was initiated to determine to what extent such evaporation takes place.

\footnotetext{
1 Central Institute for Industrial Research, PO Box 350 Blindern, N-0314 Oslo 3, Norway.

2 Lista Aluminium, PO Box 128, N-4551 Farsund, Norway.
}

Reprint requests to: Dr I Alfheim, Center for Industrial Research, PO Box 350, 0314 Oslo 3, Norway.

\section{Materials and methods}

\section{Alumina}

The alumina used in this study was primary and secondary alumina from a vertical stud Söderberg plant with $100 \%$ alumina feeding (all primary alumina passes through the dry-cleaning system). The specific surface of the alumina was in the range of $45-55$ $\mathrm{m}^{2} / \mathrm{g}$. The alumina is normally characterized with respect to several inorganic parameters before and after its use in the cleaning system. Because of a rapid, largevolume alumina stream through the dry-cleaning system, the concentrations of pollutants in the secondary alumina is relatively low. The concentrations of sulfur, fluoride, and PAH increase from below detection limits in the primary alumina to about $0.15 \%$ sulfur, $0.8 \%$ fluoride, and $100 \mathrm{ppm}$ PAH in the secondary alumina with a concomitant decrease of the $\mathrm{pH}$ from approximately 10 to about 6 .

\section{Heating of the alumina}

Unless otherwise stated, $10 \mathrm{~g}$ of secondary alumina was heated from room temperature to $360^{\circ} \mathrm{C}$ in $30 \mathrm{~min}$ in order to mimic the heating process that occurs in the smelting pots. The flue gases were collected with the equipment shown in figure 1 . In a separate experiment the reaction products were sampled for gas chromatographic-mass spectrometric analysis only, and the equipment was then simplified by the removal of the ethanol impingers and the inclusion of a glass fiber filter followed by an XAD-2 adsorbent.

\section{Analysis of polycyclic aromatic hydrocarbons}

Internal standards for PAH analysis were added to the alumina, which was subsequently extracted with etha- 


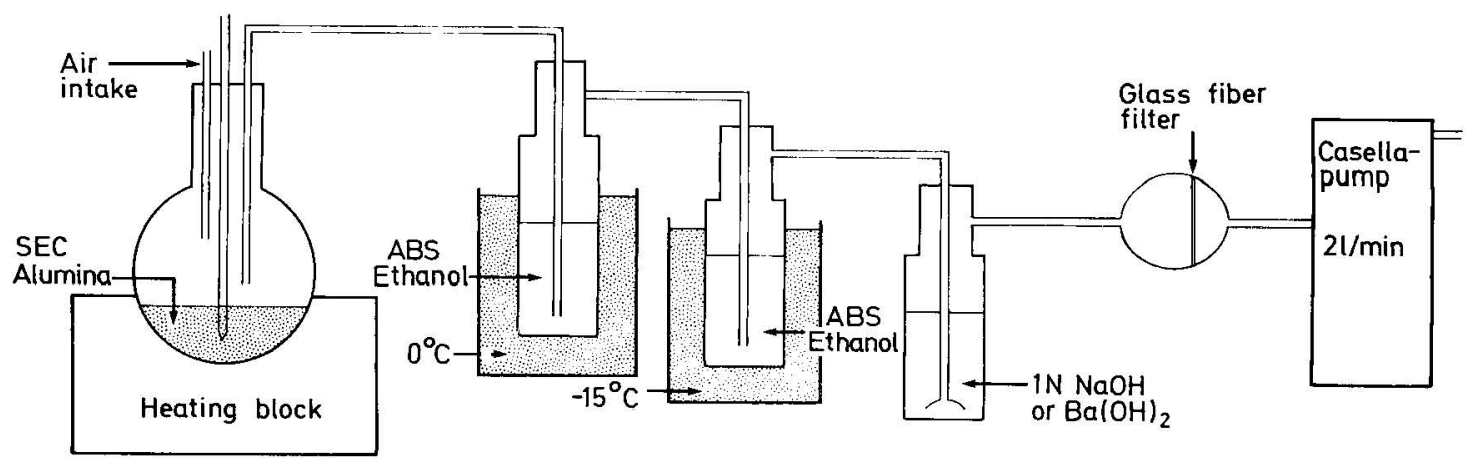

Figure 1. Equipment used for heating the secondary (SEC) alumina and collecting the vaporized compounds. [ABS $=100 \%$, $\mathrm{NaOH}=$ sodium hydroxide, $\mathrm{Ba}(\mathrm{OH})_{2}=$ barium hydroxide $]$

nol by ultrasonication for $15 \mathrm{~min}$. The ethanol extracts were shaken with cyclohexane, and the cyclohexane extracts were thereafter extracted with dimethylformamide: water $(9: 1)$ as described by Bjørseth (2) with the addition of a clean-up step consisting of passing a concentrated extract through a column of silica and eluting the column with cyclohexane. The concentrated eluate was analyzed on a Carlo-Erba gas chromatograph fitted with a glass capillary column and a flame ionization detector.

For some of the studies a simplified procedure estimating the total amount of PAH by use of thin-layer chromatography (7) was used instead of an analysis of the individual compounds.

\section{Radioactivity counting}

In a study of the mass balance, some of the alumina was spiked with ${ }^{14} \mathrm{C}$-labeled benzo-(a)pyrene (BaP). The spiking was achieved by suspending the alumina in pentane in which $[\mathrm{U}]{ }^{14} \mathrm{C}-\mathrm{BaP}[21.7 \mathrm{mCi} / \mathrm{mmol}$ $(868 \mathrm{MBq})$, the Radiochemical Centre, Amersham] was dissolved and letting the pentane evaporate as the mixture was stirred.

Various extracts of the spiked alumina were counted for radioactivity by liquid scintillation counting in a Tri-Carb spectrometer, model 3003 . Quench corrections were performed by use of the channels-ratio method.

The remaining activity on the extracted alumina was measured by suspending the alumina directly in the scintillation liquid, and the number of detectable pulses per minute was calculated by use of the internal standard method for quench corrections.

\section{Gas chromatographic-mass spectrometric analysis}

After the secondary alumina was heated, the filter used for collecting flue gases was extracted in a soxhlet apparatus with acetone for $24 \mathrm{~h}$. The solvent of the extract was then changed to methylene chloride and analyzed by gas chromatography-mass spectrometry. The system consisted of a Finnigan model 4021 quadrupole mass spectrometer equipped with a standard electron impact source. Ionization was accomplished with a $70-\mathrm{eV}$ beam of electrons generated from a heated rhenium filament with an emission current of $0.25 \mathrm{~mA}$. The source temperature was $250^{\circ} \mathrm{C}$. The electron multiplier voltage was $1700 \mathrm{~V}$.

Samples were introduced by means of a Finnigan 9610 gas chromatograph directly interfaced to the mass spectrometer by the fused silica capillary column. The typical gas chromatographic conditions were as follows: injector temperature $280^{\circ} \mathrm{C}$; interface $240^{\circ} \mathrm{C}$; carrier gas helium; linear velocity $40 \mathrm{~cm} \mathrm{~s}^{-1}$ at $100^{\circ} \mathrm{C}$; column: $30 \mathrm{~m} \times 0.25 \mathrm{~mm}$ inner diameter DB-5 (J \& W Scientific), film thickness $0.25 \mu \mathrm{m}$; column temperature program from 100 to $300^{\circ} \mathrm{C}$ at $5^{\circ} \mathrm{C} \mathrm{min}{ }^{-1}$, after initial temperature had been held for $3 \mathrm{~min}$.

Masses from 40 to 300 mass units were scanned every second. The ion data were acquired with an INCOS 2100 data system.

An acetone extract of the unheated secondary alumina was also analyzed by gas chromatography-mass spectrometry for comparison.

\section{Results}

Analyses of extracts of alumina before and after heating and of the collected flue gases

When extracts of secondary alumina were analyzed for PAH before and after heating, it was found that the extractable PAH decreased rapidly with the temperature (figure 2). The decrease was also found to be dependent on the time of heating, as illustrated in figure 3.

An analysis of the impinger solutions revealed quite unexpectedly that, when the alumina was heated to $340^{\circ} \mathrm{C}$ or above for a period of $30 \mathrm{~min}$, no PAH could be detected in the impinger solutions. Gas chromatograms of cyclohexane extracts of the impinger solutions revealed a complex pattern of peaks different from that of the unheated secondary alumina. These peaks represented compounds which were mostly more volatile than the PAH present in extracts from unheated alumina. Most of the chromatographic peaks disappeared when the sample was applied on a column 
of silica gel and eluted with cyclohexane, an indication that they represented more polar compounds than the PAH.

A further characterization of the compounds that could be found in aerosols above the heated secondary alumina was performed by a gas chromatographmass spectrometer analysis of the extracts from the aerosol collected on a glass fiber filter in a separate experiment. This analysis demonstrated that some of the most stable $\mathrm{PAH}$ compounds may evaporate from the secondary alumina during the heating process, eg, fluoranthene and chrysene/triphenylene. Most of the compounds identified were, however, oxidation products of PAH. The results are given in table 1. Figure 4 shows chromatograms of the extract of unheated secondary alumina and of the extract from the sample collected on a filter during the heating of the alumina. The chromatograms showed distinct differences and therefore demonstrated that the vapors evolved during heating have a different constitution than the PAH on the secondary alumina.

\section{Mass balance of the adsorbed polycyclic aromatic hydrocarbons upon heating of the secondary alumina}

The analyses had given qualitative information that the PAH on the alumina had not simply evaporated, but had been subjected to breakdown reactions. The quantitative aspect of the breakdown was studied by a mass balance estimation of the process. This mass balance was performed with secondary alumina spiked with radiolabeled $\mathrm{BaP}$. Aliquots of extracts of heated and unheated alumina, of the alumina itself, of impinger solutions, and of the ethanol extract of the filter (figure 1) were counted for radioactivity. The results from two parallel experiments are presented in table

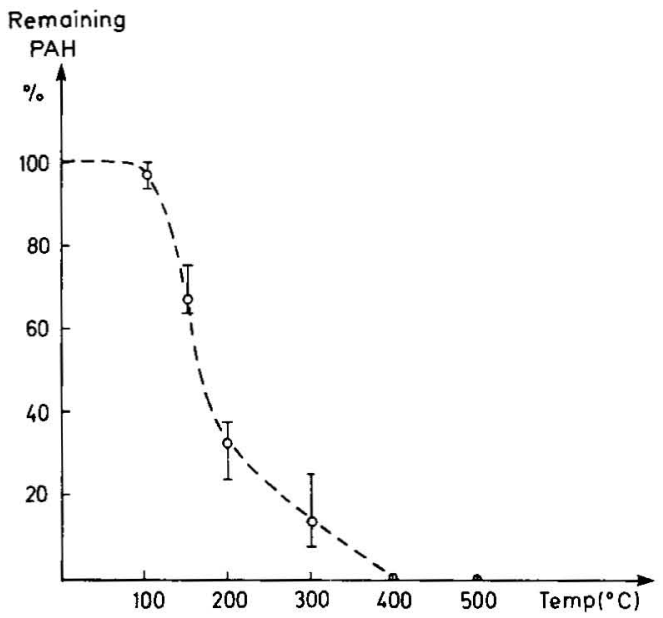

Figure 2. Remaining polycyclic aromatic hydrocarbons (PAH) on secondary alumina after heating for $1 \mathrm{~h}$ as a function of heating temperature (temp).
2. As the counting of the impinger solutions revealed unexpectedly low counts, the heated alumina was extracted several times and with acetone extraction following three consecutive ethanol extractions. A counting of dispersed samples of the remaining alumina showed that, whereas nearly all radioactivity could be extracted from the nonheated alumina, $54 \%$ of the total radioactivity added remained unextracted when the alumina had been heated. The total recovery of radioactivity from the heated alumina was about $75 \%$ compared to the nearly complete recovery from the unheated alumina. The loss of about $25 \%$ could possibly be explained by an inefficient counting of the solid samples, but it was more likely caused by very volatile compounds passing through the impinger solutions. As indicated by the counting results for the sodium and barium hydroxide solutions included to trap carbon dioxide, the total breakdown to carbon dioxide and water was nearly negligible.

The radioactivity that was extracted from the heated alumina represented at most $25 \%$ of the radioactivity still associated with the alumina. Gas chromatography of these extracts showed that no BaP could be detected. As the amount of radioactivity in these extracts corresponded to $27 \mu \mathrm{g} \mathrm{BaP}$ (combined extracts from experiment 2), which is far more than the detection limit (100 ng), the extracted activity must represent reaction products derived from BaP. During the preparation of the extract for PAH analysis, a solvent partitioning into a nonpolar fraction, a PAH fraction, and a more polar fraction was performed (2). When aliquots of concentrates of these fractions were counted for radioactivity, $47 \%$ of the activity was found in the most polar fraction, whereas the nonpolar and the PAH fraction contained 0.3 and $9.6 \%$, respectively. The remaining $43.1 \%$ was lost, probably through evaporation during the concentration of the fractions, and thus most likely represents volatile compounds.

Remaining PAH

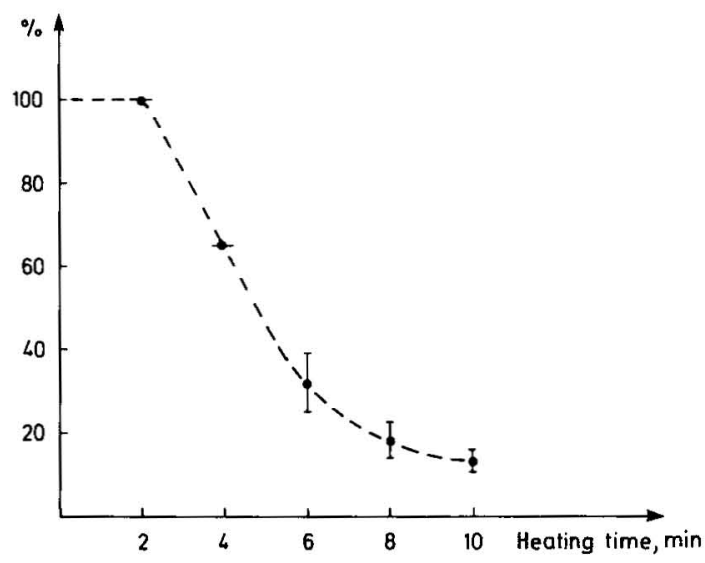

Figure 3. Remaining polycyclic aromatic hydrocarbons (PAH) on secondary alumina after heating to $350^{\circ} \mathrm{C}$ as a function of heating time. 
Table 1. Polycyclic aromatic compounds on secondary alumina before heating (alumina) and trapped on the filter after heating (filter). The abundance is given relative to that of fluoranthene. (PAH = unidentified polycyclic aromatic hydrocarbons)

\begin{tabular}{|c|c|c|c|c|c|}
\hline \multirow{2}{*}{ Compound } & \multirow{2}{*}{$\begin{array}{c}\text { Molecular } \\
\text { weight }\end{array}$} & \multicolumn{2}{|c|}{ Alumina } & \multicolumn{2}{|c|}{ Filter } \\
\hline & & Scan & $\begin{array}{c}\text { Relative } \\
\text { abundance }\end{array}$ & Scan & $\begin{array}{c}\begin{array}{c}\text { Relative } \\
\text { abundance }\end{array}\end{array}$ \\
\hline Dibenzofurane & 168 & 712 & 0.051 & . & - \\
\hline Fluorene & 166 & 803 & 0.043 & . & - \\
\hline Xanthene & 182 & 876 & 0.005 & . & - \\
\hline Fluorenone & 180 & 1108 & 0.050 & 1054 & 1.296 \\
\hline Dibenzothiophene & 184 & 1135 & 0.036 & 1074 & 0.012 \\
\hline Phenanthrene & 178 & 1187 & 0.482 & 1129 & 0.226 \\
\hline Acridine/benzoquinoline & 179 & 1206 & 0.012 & . & - \\
\hline Acridine/benzoquinoline & 179 & 1228 & 0.003 & . & - \\
\hline Acridine/benzoquinoline & 179 & 1267 & 0.034 & & - \\
\hline Methylfluorenone & 194 & & - & 1218 & 0.030 \\
\hline Naphthalendicarboxylic acid anhydride & 198 & 1352 & 0.013 & 1246 & 0.024 \\
\hline Methylfluorenone & 194 & . & - & 1306 & 0.006 \\
\hline Chlorofluorenone (?) & 214 & . & - & 1348 & 0.014 \\
\hline Chlorofluorenone (?) & 214 & : & - & 1368 & 0.015 \\
\hline 3-Methylphenanthrene & 192 & 1384 & 0.026 &. & - \\
\hline 2-Methylphenanthrene & 192 & 1393 & 0.050 & : & - \\
\hline 4,5-Methylenephenanthrene & 190 & 1417 & 0.020 & . & - \\
\hline 4-Methylphenanthrene & 192 & 1423 & 0.005 & $\dot{.}$ & - \\
\hline 1-Methylphenanthrene & 192 & 1430 & 0.014 & ${ }^{\circ}$ & - \\
\hline Xanthenone & 196 & 1473 & 0.019 & 1437 & 0.550 \\
\hline Anthraquinone & 208 & 1500 & 0.065 & 1464 & 0.484 \\
\hline Dibenzothiophenquinone & 214 & & - & 1499 & 0.010 \\
\hline Cyclopenta(def)phenanthrenone & 204 & 1600 & 0.012 & 1563 & 0.058 \\
\hline $\begin{array}{l}\text { Fluoranthene } \\
\text { fol }\end{array}$ & 202 & 1621 & 1.000 & 1587 & 1.000 \\
\hline Pyrene & 202 & 1686 & 0.440 & 1649 & 0.059 \\
\hline Ethylmethylenephenanthrene & 218 & 1698 & 0.093 & & - \\
\hline Pyrenone/fluoranthenone & 218 & 1719 & 0.024 & 1665 & 0.114 \\
\hline Pyrenone/fluoranthenone & 218 & 1738 & 0.058 & 1686 & 0.075 \\
\hline Pyrenone/fluoranthenone & 218 & & - & 1705 & 0.029 \\
\hline Benzo(a)fluorene & 216 & 1775 & 0.046 &. & - \\
\hline Benzo(b)fluorene & 216 & 1779 & 0.065 & . & - \\
\hline Methylpyrene & 216 & 1808 & 0.072 & 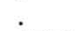 & - \\
\hline Nitroanthracene & 223 & 1812 & Trace & 1783 & 0.050 \\
\hline Nitroanthracene & 223 & & - & 1792 & 0.010 \\
\hline Methylpyrene & 216 & 1828 & 0.047 & . & - \\
\hline Methylpyrene & 216 & 1834 & 0.019 & . & - \\
\hline Chloropyrene & 236 & & - & 1848 & 0.032 \\
\hline Benzo(a)anthracenone (?) & 244 & 1907 & 0.006 & 1883 & 0.012 \\
\hline Chrysenone (?) & 244 & 1943 & 0.012 & 1920 & 0.014 \\
\hline Benzo(a)fluorenone & 230 & 1964 & 0.055 & 1939 & 0.244 \\
\hline Benzonaphthothiophene & 234 & 1992 & 0.168 & 1965 & 0.094 \\
\hline Benzo(c)fluorenone & 230 & 1999 & 0.033 & 1973 & 0.044 \\
\hline Benzo(ghi)fluoranthene & 226 & 2003 & 0.039 & . & - \\
\hline Benzo(c)phenanthrene & 228 & 2006 & 0.040 & : & - \\
\hline Benzacridine & 229 & 2016 & 0.023 & . & - \\
\hline Benzonaphthothiophene & 234 & 2019 & 0.026 & 1992 & 0.012 \\
\hline Benzo(b)fluorenone & 230 & 2027 & 0.042 & 2003 & 0.211 \\
\hline Benzonaphthothiophene & 234 & 2042 & 0.025 & & - \\
\hline Benz(a)anthracene & 228 & 2065 & 0.329 & 2039 & 0.013 \\
\hline Chrysene/triphenylene & 228 & 2078 & 0.845 & 2053 & 0.406 \\
\hline Benz(de)anthracenone & 230 & 2111 & 0.006 & 2087 & 0.020 \\
\hline Benzophenanthridine & 229 & 2118 & 0.003 & & - \\
\hline Nitrofluoranthene & 247 & . & - & 2139 & 0.011 \\
\hline Nitrofluoranthene & 247 & & - & 2144 & 0.016 \\
\hline Methylchrysene & 242 & 2192 & 0.045 & $.0+7$ & - \\
\hline Methylchrysene & 242 & 2202 & 0.023 & . & - \\
\hline Benzoantraquinone & 258 & 2205 & 0.011 & & - \\
\hline Nitropyrene & 247 & 2220 & 0.035 & 2192 & 0.006 \\
\hline Nitropyrene & 247 & . & - & 2198 & 0.003 \\
\hline Benzanthraquinone & 258 & . & - & 2262 & 0.010 \\
\hline Benzo(cd)pyrenone & 254 & & - & 2326 & 0.016 \\
\hline Benzo(b, $j$ and $k$ )-fluoranthenes & 252 & 2366 & 0.933 & 2346 & 0.207 \\
\hline Phenanthroquinoline & 253 & 2329 & 0.027 & . & - \\
\hline Phenanthroquinoline & 253 & 2415 & 0.022 & & - \\
\hline Benzo(e)pyrene & 252 & 2432 & 0.374 & 2410 & 0.076 \\
\hline Benzo(a)pyrene & 252 & 2442 & 0.064 & & - \\
\hline Nitrobenz(a)anthracene & 273 & & - & 2463 & 0.019 \\
\hline Methylbenzo(e)pyrene & 266 & 2480 & 0.023 & . & - \\
\hline Methylbenzo(a)pyrene & 266 & 2531 & 0.013 & & - \\
\hline Benzo(a)pyrenquinone & 282 & & - & 2516 & 0.007 \\
\hline Benzophenanthrothiophene & 284 & 2665 & 0.007 & . & - \\
\hline Benzophenanthrothiophene & 284 & 2668 & 0.014 & . & - \\
\hline PAH & 278 & 2685 & 0.050 & . & - \\
\hline
\end{tabular}


Table 1. Continued.

\begin{tabular}{|c|c|c|c|c|c|}
\hline \multirow[b]{2}{*}{ Compound } & \multirow[b]{2}{*}{ Mw } & \multicolumn{2}{|c|}{ Alumina } & \multicolumn{2}{|c|}{ Filter } \\
\hline & & Scan & $\begin{array}{c}\text { Relative } \\
\text { abundance }\end{array}$ & Scan & $\begin{array}{c}\text { Relative } \\
\text { abundance }\end{array}$ \\
\hline Indeno(1, 2, 3-cd)pyrene & 276 & 2703 & 0.133 & . & - \\
\hline PAH & 278 & 2713 & 0.042 & . & - \\
\hline Dibenzanthracene & 278 & 2734 & 0.020 & . & - \\
\hline Dibenzanthracene & 278 & 2741 & 0.029 & . & - \\
\hline Benzo(ghi)fluoranthene & 276 & 2755 & 0.160 & . & - \\
\hline PAH & 302 & 2992 & 0.032 & . & _- \\
\hline PAH & 302 & 3010 & 0.027 & . & - \\
\hline Coronene & 300 & 3085 & 0.011 & . & - \\
\hline PAH & 302 & 3094 & 0.011 & . & - \\
\hline PAH & 302 & 3100 & 0.009 & . & - \\
\hline
\end{tabular}
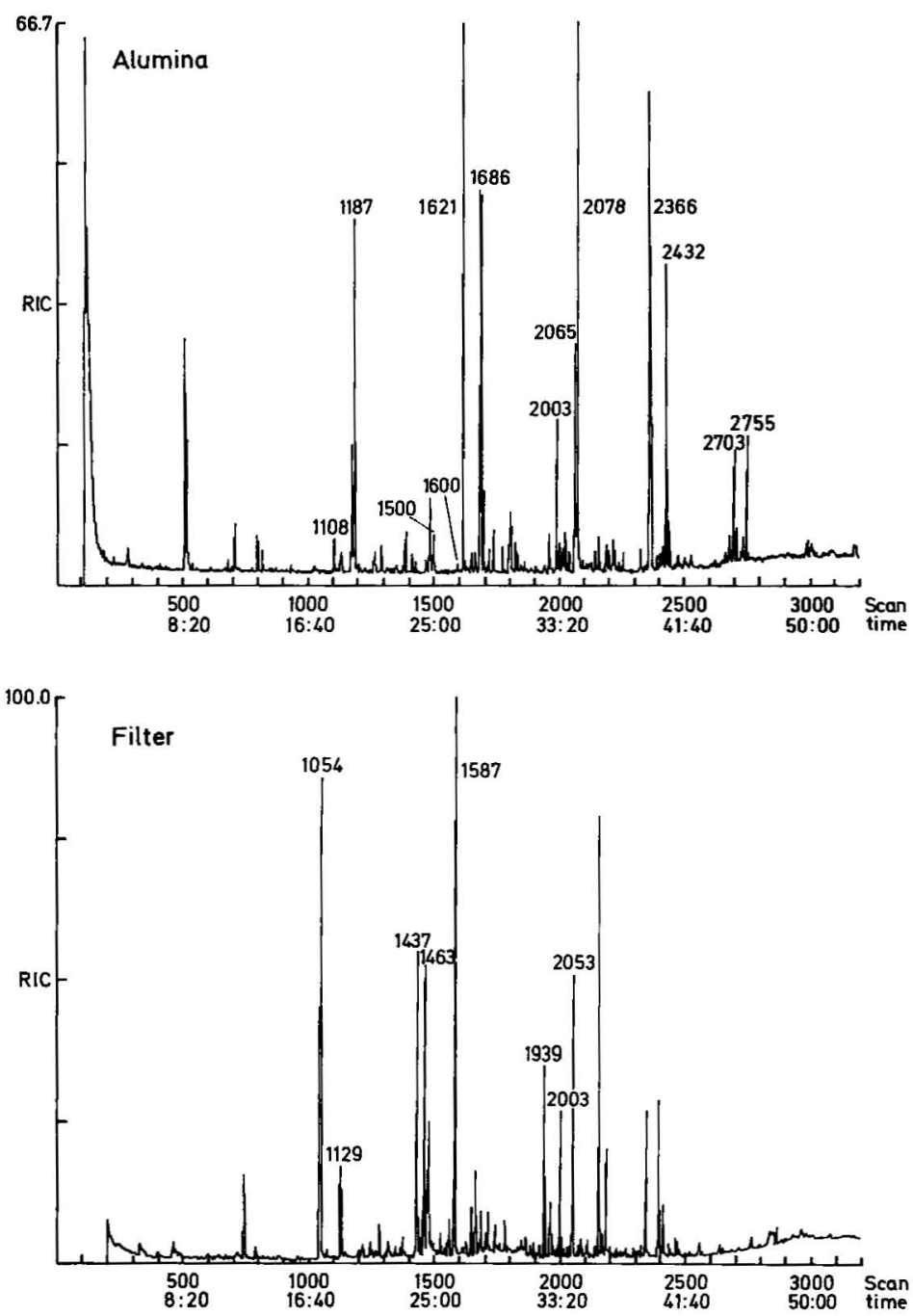

Figure 4. Chromatograms of acetone extracts of unheated secondary alumina and of the glass fiber filter after heating. For the peak assignments, see table 1.

Attempts to extract the remaining polycyclic aromatic hydrocarbons from heated secondary alumina

Three hypotheses could be suggested to explain why such a large part of the PAH on heated secondary alu- mina remained unextracted: (i) all of the PAH may be transformed (oxidized) to more polar compounds, which are bound more firmly to the surface of the alumina; (ii) the PAH compounds may have condensed to larger ring systems, which are bound tighter to the 
Table 2. Recovery of radioactivity from secondary aluminum oxide spiked with ${ }^{14} \mathrm{C}$-benzo(a)pyrene in two different experiments after heating to $360^{\circ} \mathrm{C}$.

\begin{tabular}{|c|c|c|c|c|c|}
\hline \multirow[b]{2}{*}{ Sample a } & \multicolumn{5}{|c|}{ Radioactivity $10^{6} \mathrm{dpm} / \mathrm{g}$ oxide } \\
\hline & $\begin{array}{l}\text { Ethanol } \\
\text { extracts }\end{array}$ & $\begin{array}{l}\text { Acetone } \\
\text { extracts }\end{array}$ & $\begin{array}{l}\text { Remaining } \\
\text { on the oxide }\end{array}$ & Total & $\begin{array}{l}\text { Percentage of } \\
\text { added activity }\end{array}$ \\
\hline \multicolumn{6}{|c|}{ Untreated secondary oxide } \\
\hline \multirow[t]{2}{*}{ Experiment 1} & $\begin{array}{l}3.89^{b} \\
0.32 \\
\end{array}$ & & & & \\
\hline & $\overline{4.21}$ & 0.36 & 0.30 & 4.87 & 100 \\
\hline \multirow[t]{2}{*}{ Experiment 2} & $\begin{array}{l}2.04^{b} \\
0.43 \\
0.06 \\
\end{array}$ & & & & \\
\hline & 2.53 & 0.05 & 0.41 & 2.99 & 91.7 \\
\hline \multicolumn{6}{|c|}{ Heated secondary oxide } \\
\hline \multirow[t]{2}{*}{ Experiment 1} & $\begin{array}{l}0.46^{b} \\
0.15 \\
0.05 \\
\end{array}$ & & & & \\
\hline & 0.66 & 0.23 & 2.63 & 3.52 & 72 \\
\hline \multirow[t]{2}{*}{ Experiment 2} & $\begin{array}{l}0.38^{b} \\
0.16 \\
\underline{0.08} \\
\end{array}$ & & & & \\
\hline & 0.62 & 0.07 & 1.73 & 2.42 & 74.2 \\
\hline \multicolumn{6}{|c|}{ Impinger solutions } \\
\hline Experiment 1 & $\begin{array}{l}0.004^{c} \\
0.001^{2}\end{array}$ & . & $\cdot$ & 0.01 & 0 \\
\hline \multicolumn{6}{|l|}{ Ethanol } \\
\hline Experiment 2 & $\begin{array}{l}0.003^{c} \\
0.001\end{array}$ & . & . & 0.00 & 0.0 \\
\hline \multicolumn{6}{|l|}{ Sodium hydroxide } \\
\hline Experiment 1 & . & . & . & 0.06 & 1.3 \\
\hline \multicolumn{6}{|l|}{ Barium hydroxide } \\
\hline Experiment 2 & . & . & . & 0.04 & 1.3 \\
\hline
\end{tabular}

alumina surface; and (iii) the PAH as such may form coordination complexes with the alumina surface due to alterations in the surface.

In an investigation of which of these theories was the most likely, the experiment using radiolabeled $\mathrm{BaP}$ coated on the alumina was repeated once more. This time the alumina was extracted by ultrasonication eight times successively with various solvents. Aliquots from all the extracts were counted for radioactivity. The results are illustrated in figure 5. Dimethylformamide was found to be more efficient than ethanol for the heated alumina, and $42 \%$ of the added activity was recovered from the heated alumina after three successive extractions with ethanol followed by three extractions with dimethylformamide, as opposed to $92 \%$ for the unheated alumina.

No BaP could be detected in any of the extracts from the heated alumina when subjected to PAH analysis. This result was in contrast to results from the extracts of the unheated alumina, which contained $7.6 \mathrm{ppm}$ in the combined ethanol extracts and another $0.7 \mathrm{ppm}$ in the dimethylformamide extracts.
Treatment of the heated alumina with hydrogen fluoride released most of the remaining radioactivity. Subsequent extraction of the hydrogen fluoride slurry with cyclohexane and dichloromethane showed that most of the activity was extracted with dichloromethane. No BaP could be detected in any of the extracts.

\section{Discussion}

The results from the analysis of the hydrogen fluoride slurry extracts point towards our hypothesis $i$ as the most likely, ie, that the PAH are oxidized to more polar compounds which are bound more firmly to the surface of the alumina. If the radiolabeled $\mathrm{BaP}$ had been bound to the alumina surface as part of a larger condensed system or as a coordination complex, it is likely that the treatment with hydrogen fluoride would have produced compounds that were more easily extracted into cyclohexane. 
There is ample evidence that most PAH undergo photooxidation in solution, as pure solids and even when adsorbed to certain solid substrates (13). The photodecomposition products are mainly ketones and quinones (11). Hydroxy and dihydroxy derivatives are less abundant.

Similar oxidation products may also be formed in the dark when PAH compounds are adsorbed to a solid carrier, but not when the compounds exist in their crystalline form or in solution (11). The rate of the oxidations taking place in the dark depends mainly on the adsorption substrate (11). An adsorptive association of PAH on silica and alumina tends to increase their susceptibility to photooxidative attacks, whereas nonphotochemical degradation of, eg, fluorene has not been observed on these surfaces (11). Adsorption on coal fly ash stabilizes the PAH against photochemical attack, but at the same time nonphotochemical oxidation is permitted to occur (11). Fitch \& Smith (6) have found the oxidized PAH to be more readily extracted from the carrier than the parent $\mathrm{PAH}$, an observation that disfavors our hypothesis i.

A theory involving complex formation has been suggested by Fox \& Olive (8) and by Thomas et al (15). Fox \& Olive suggested that exitation by, eg, light can initiate polymerization pathways which lead to highly condensed systems. Thomas et al (15) studied the influence of surface area on the photolytic degradation of BaP. On the basis of their observations, they formed a theory that represents a combination of the three hypotheses listed by us. They suggested that, as undissociated $\mathrm{BaP}$ is very reactive, it readily enters into equilibrium involving complex formation upon activation by light or heat. The complex thus formed is possibly a dimer which locks the $\mathrm{C}-\mathrm{H}$ out-of-plane vibrations to one side of the plane. This complex may enter into further complex formation through hydrogen bonding to hetero atoms. As $\mathrm{BaP}$ readily undergoes oxidation, this hydrogen bonding may occur also to oxidation products of the parent compound (15). Studies of the reactions between PAH adsorbed on solid surfaces and oxides of nitrogen and sulfur have been reported by several authors $(9,14)$.

Even if our results are partly inconclusive with respect to what compounds are formed on the alumina, it seems fairly certain that most of the PAH present on secondary alumina is not given off to the ambient air upon heating.

A limitation of the experimental system is that the $\mathrm{BaP}$ spiked on the secondary alumina does not necessarily behave exactly as the PAH adsorbed during the cleaning process. However, if there is a difference, it would be most likely that the spiked PAH are less strongly adsorbed and consequently even more unlikely to evaporate to the work environment during the smelting process.

The validity of our conclusion may also be limited by the fact that the experimental system is different from the situation occurring when secondary alumina

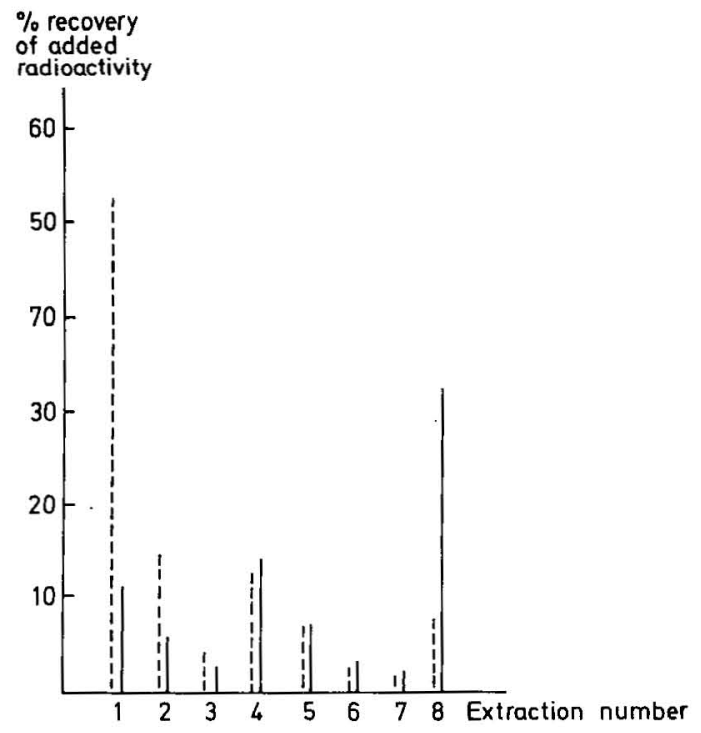

Figure 5. Recovery of radioactivity upon eight successive extractions with different solvents of unheated $(--)$ and heated (-) secondary alumina. $(1=$ ethanol, $2=$ ethanol, $3=$ ethanol, $4=$ dimethylformamide, $5=$ dimethylformamide, $6=$ dimethylformamide, $7=$ tetrahydrofurane, $8=$ hydrogen fluoride)

is used in the smelting pots. The results obtained in this study should be verified in comparisons of PAH concentrations in samples collected from pots operated with primary and secondary alumina.

\section{Acknowledgments}

Ms MB Støbet and Ms A Osvik are thanked for their skillful technical assistance.

Financial support from the Nordic Aluminum Industries Secretariat for Health, Environment and Safety, Oslo, and from the Jahre-Wellcome Foundation is gratefully acknowledged.

\section{References}

1. Alfheim I, Wikstrøm L. Air pollution from aluminum smelting plants: I. Toxicol Environ Chem 8 (1984) 55-72.

2. Bjørseth A. Analysis of polycyclic aromatic hydrocarbons in particulate matter by glass capillary gas chromatography. Anal Chem Acta 94 (1977) 21-27.

3. Bjørseth A, Bjørseth O, Fjeldstad PE. Polycyclic aromatic hydrocarbons in the work atmosphere: I Determination in an aluminum reduction plant. Scand $\mathbf{J}$ Work Environ Health 4 (1978) 212-223.

4. Bjørseth A, Bjørseth O, Fjeldstad PE. Polycyclic aromatic hydrocarbons in the work atmosphere: Determination of area-specific concentrations and job-specific exposure in a vertical pin Söderberg aluminum plant. Scand J Work Environ Health 7 (1981) 223-232.

5. Bjørseth A, Lunde G. Analysis of the polycyclic aromatic hydrocarbon content of airborne particulate pollutants in a Söderberg paste plant. Am Ind Hyg Assoc J 38 (1977) 224-228.

6. Fitch WL, Smith DH. Analysis of adsorption properties and adsorbed species on commercial polymeric car- 
bons. Environ Sci Technol 13 (1979) 341-346.

7. Fjeldstad PE, Halgard K. PAH, thin-layer-chromatography. Norwegian Institute for Industrial Hygiene, Oslo 1976. (HD 696/76.11.22.)

8. Fox MA, Olive S. Photooxidation of anthracene on atmospheric particulate matter. Science 205 (1979) $582-583$

9. Jäger J, Rakovic M. Sulfur dioxide-induced qualitative changes in polycyclic aromatic hydrocarbons adsorbed on solid carriers. J Hyg Epidemiol Microbiol Immunol 18 (1974) 137-143.

10. Konstantinov VG, Kys'minykh AI. Resinous substances and 3,4-benzpyrene in the air of electrolysis shops of aluminum plants and their role in carcinogenesis [in Russian]. Hyg Sanit 36 (1971) 39-42. (Chemical Abstracts 74 (1971) 1459949).

11. Korfmacher WA, Natusch DFS, Taylor DR, Mamantov G, Wehry EL. Oxidative transformations of polycyclic aromatic hydrocarbons adsorbed on coal fly ash.
Science 207 (1980) 763-765.

12. Lindstedt G, Sollenberg J. Polycyclic aromatic hydrocarbons in the occupational environment: With special reference to benzo(a)pyrene measurements in Swedish industry. Scand J Work Environ Health 8 (1982) 1-19.

13. National Academy of Science. Biological effects of atmospheric pollutants: Particulate polycyclic organic matter. Washington, DC 1972.

14. Nielsen T, Ramdahl T, Bjørseth A. The fate of airborne polycyclic organic matter. Environ Health Perspec 47 (1983) 103-114.

15. Thomas JF, Mukai M, Tebbens BD. Fate of airborne benzo(a)pyrene. Environ Sci Technol 2 (1968) 33-39.

Received for publication: 10 December 1984 